Miniperspective

\title{
Protein chemical synthesis in medicinal chemistry
}

Vangelis Agouridas, ${ }^{\mathrm{a}, \mathrm{b} *}$ Ouafâa El Mahdi, ${ }^{\mathrm{c}}$ Oleg Melnyk ${ }^{\mathrm{a} *}$

a Univ. Lille, CNRS, Inserm, CHU Lille, Institut Pasteur de Lille, U1019 - UMR 9017 - CIIL Center for Infection and Immunity of Lille, F-59000 Lille, France

${ }^{\mathrm{b}}$ Centrale Lille, F-59000 Lille, France

${ }^{c}$ University Sidi Mohamed Ben Abdellah, Faculté Polydisciplinaire de Taza, BP 1223 Taza gare, Morocco.

Corresponding authors

Oleg.melnyk@ibl.cnrs.fr

Vangelis.agouridas@ibl.cnrs.fr 


\begin{abstract}
Although the majority of proteins used for biomedical research are produced using living systems such as bacteria, biological means for producing proteins can be advantageously complemented by protein semisynthesis or total chemical synthesis. The latter approach is particularly useful when the proteins to be produced are toxic for the expression system or show unusual features that cannot be easily programmed in living organisms. The aim of this perspective article is to provide a wide overview of the use of protein chemical synthesis in medicinal chemistry with a special focus on the production of side-chain or backbone-modified proteins.
\end{abstract}

\title{
INTRODUCTION
}

The discovery of powerful methods such as solid phase peptide synthesis (SPPS) has accelerated the elucidation of the mode of action of biologically active peptides and the study of their structure-function relationships. As such, the SPPS has fueled the development of peptide therapeutics as well as facilitated their GMP compliant large-scale production. More than a hundred peptides are currently under development in various therapeutic areas that include metabolic diseases, oncology, and cardiovascular diseases. ${ }^{1}$ Until the 1990 s, peptide synthesis methods were limited to the production of polypeptides having less than 40-50 amino acids (AA), and the chemical synthesis of small proteins required considerable efforts. Since then, the domain has witnessed substantial conceptual and technical advances with the advent of chemoselective amide bond forming reactions, also referred to as native ligation reactions. ${ }^{2-}$

${ }^{4}$ By enabling the coupling of unprotected peptide segments in aqueous media, these methods have facilitated the production of large and highly modified proteins by semi or total chemical synthesis. Such synthetic studies are frequently integrated as part of research programs towards 
the understanding of protein function in relation to therapeutic interventions based on small molecules (Figure 1). Also, endogenous proteins or proteins derived from other natural sources (animals and plants) constitute a large reservoir of inspiration for the development of therapeutic proteins. In recent years, such approaches have been the focus of numerous studies and are now greatly supported by the richness of the protein chemist's toolbox.

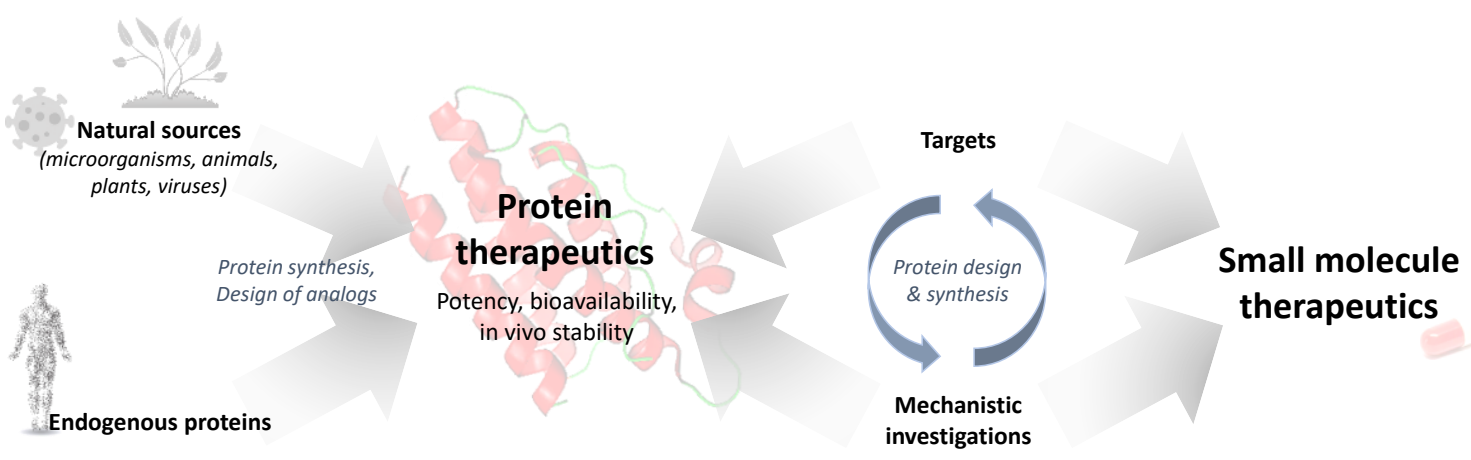

Figure 1. Protein semi or total synthesis is sustained by the development of small-molecule drugs and protein therapeutics derived from a variety of animals and plants.

The number of proteins prepared by semi or total chemical synthesis has been expanding rapidly since 2010, showing that the developed chemistries fill a gap and respond to important needs in chemical biology research (Figure 2a). This corpus of methods enabled the production of proteins with a mean size of 90 AA obtained through total chemical synthesis (Figure 2b) and nearly 200 AA through semi-synthesis (Figure 2c). 
a)

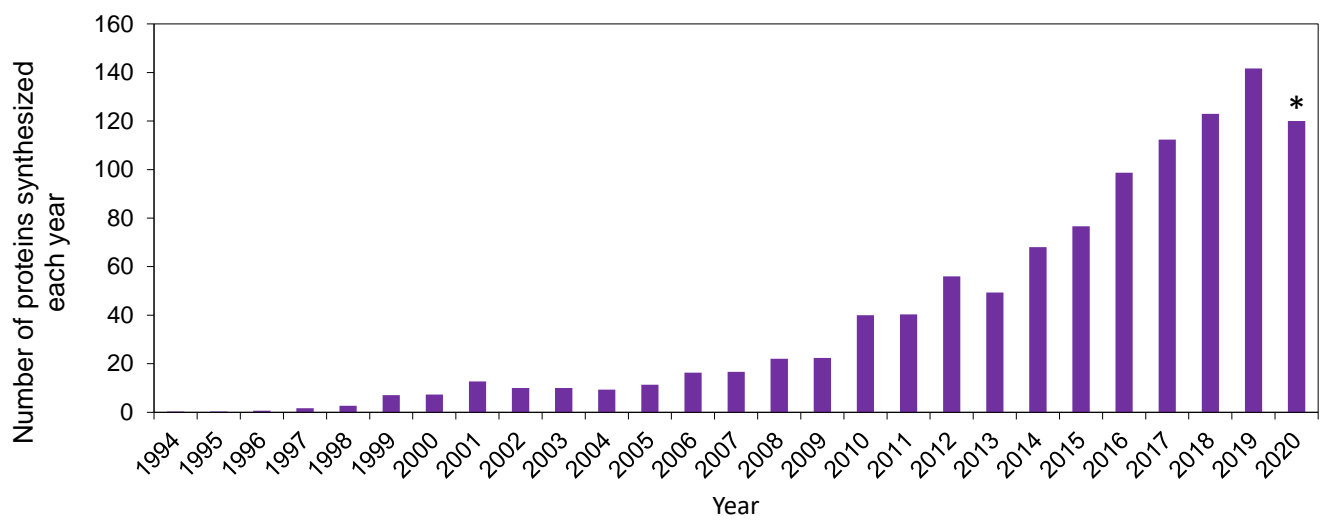

b)
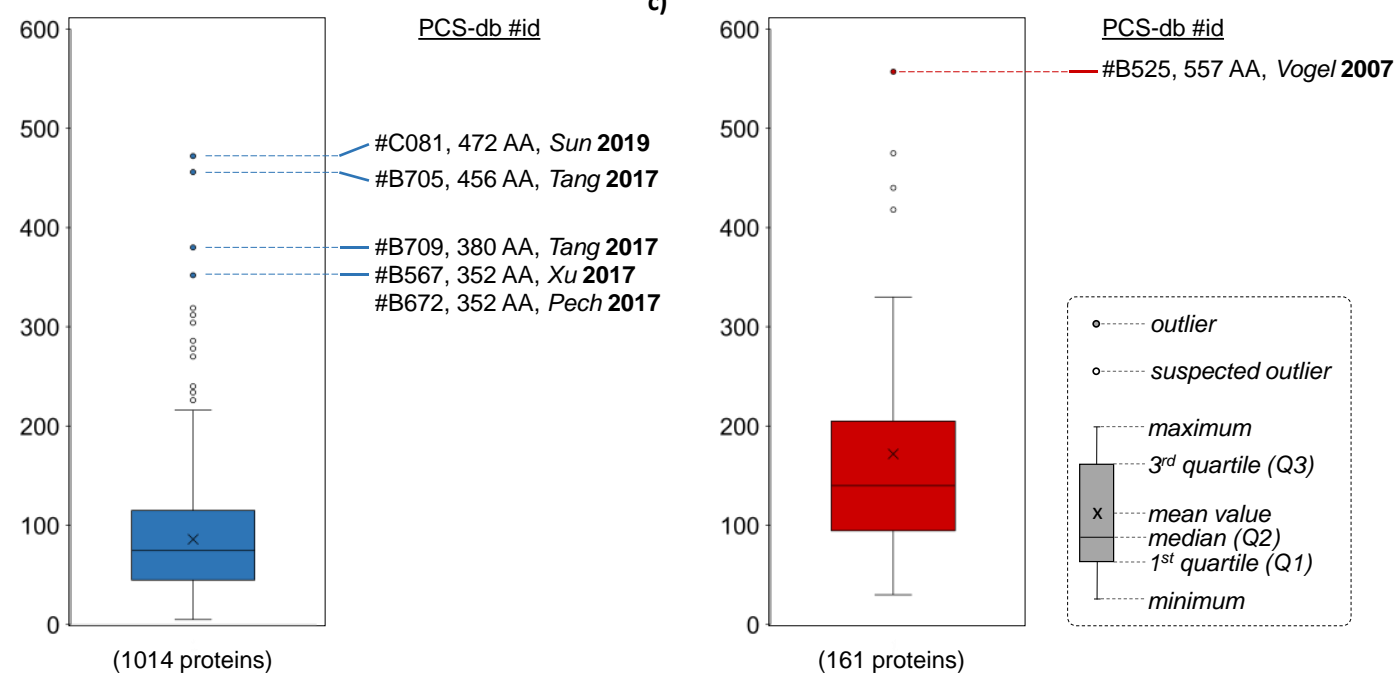

Figure 2. a) Number of proteins produced by semisynthesis or total chemical synthesis by means of chemoselective amide-bond forming reactions, each year since 1994. For year $i$, data are represented as the moving average of years $i-2, i-1$ and $i$. Only partial data are available for 2020. b) Box-and-whisker plot representation of the size of synthetic proteins produced in the period 1994-2020. Outliers are defined as datapoints above Q3 + $3 \times(\mathrm{Q} 3-\mathrm{Q} 1)$. Suspected outliers are defined as datapoints between $\mathrm{Q} 3+1.5 \times(\mathrm{Q} 3-\mathrm{Q} 1)$ and $\mathrm{Q} 3+3 \times(\mathrm{Q} 3-\mathrm{Q} 1)$. c) Boxand-whisker plot representation of the size of semisynthetic proteins produced in the period 1994-2020. Data are extracted from the Protein Chemical Synthesis Database (PCS-db, http://pcs-db.fr). ${ }^{5}$ The proteins cited in this figure and the following ones in this Perspective are identified by a PCS-db identification number. This PCS-db \#id enables easy retrieval of the 
reference and the information on how the protein was produced using the PCS-db ID interface (PCS-ID).

In this perspective, we provide a broad overview of the use of protein chemical synthesis for applications in medicinal chemistry with a special focus on its main asset, which is the production of side-chain or backbone-modified proteins (Figure 3). The first section presents the main strategies used for accessing proteins by semi or total synthesis. For the non-specialist, identifying the best synthetic route to a protein target is not an easy task. Hopefully, newly developed decision-support tools, which are available in the form of programs or databases, can provide useful assistance for the design of a synthetic plan. One of these is the Protein Chemical Synthesis database (http://pcs-db.fr), a web-based tool, which inventories biologically relevant peptides and proteins synthesized using chemoselective amide bond forming reactions (> 1000 entries). ${ }^{5}$ The content of the PCS database can be interrogated thanks to various search modules, each proposing a large diversity of descriptors for the synthetic design (PCS-db) or for the type of modifications harbored by the proteins (as in the freshly released PCS post-translational modifications module, $\underline{\text { PCS-PTM}})$. As such, the PCS database and its web-based tools can be considered as a helping-hand for any chemist willing to integrate the synthesis of tailored peptides or proteins in their research work. Browsing the PCS database using the protein identification numbers in the Figures provides a useful complement to the reading of this Perspective by giving the key information on how the cited proteins were produced ( $\underline{\text { PCS-ID)}}$.

The second section gives a description of the main modifications that have been effected by protein chemists and that are relevant for the medicinal chemist. In particular, this section will cover the production of proteins harboring post-translational modifications (PTMs) and their use for deciphering protein function. The third section will discuss the use of protein chemical 
synthesis as a tool for deciphering biological mechanisms, for target identification and for accessing potential therapeutic proteins.

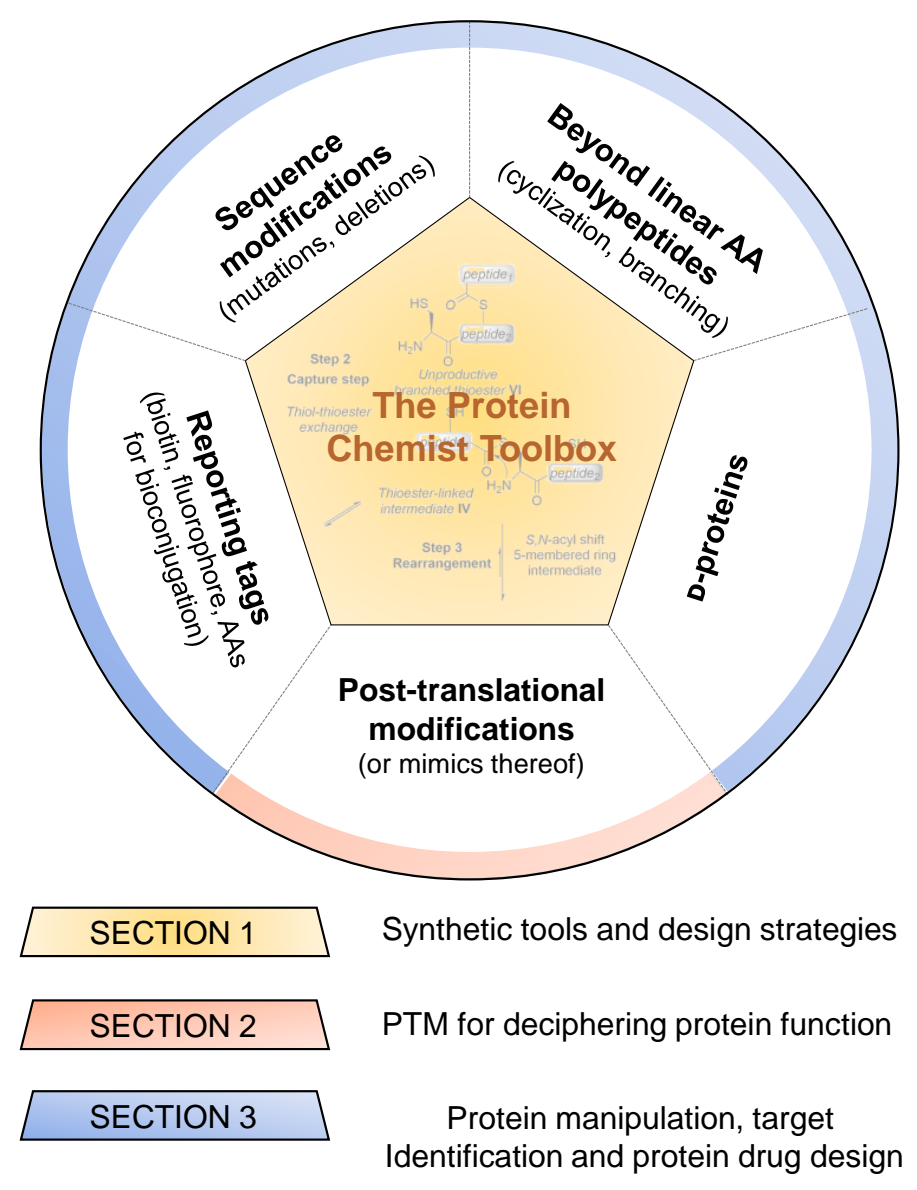

Figure 3. Scope and content of the Perspective.

\section{DISCUSSION}

\section{The semi or total chemical synthesis of proteins}

Conceptually, the peptide segment coupling methods used for modern protein synthesis differ from classical amide coupling techniques based on the enthalpic activation of carboxylic acids by involving first a chemoselective capture step, which brings the $\mathrm{N}$ and $\mathrm{C}$-terminal functionalities close in space (Figure 4a). During this step, the peptide segments get covalently 
linked by a non peptidic bond. The connecting native peptide bond is formed subsequently after a spontaneous intramolecular rearrangement. The most popular set of techniques used thus far for protein synthesis is undoubtedly native chemical ligation $\left(\mathrm{NCL}^{2}\right)$ and associated methods. ${ }^{5-}$

${ }^{7}$ In this case, the reacting partners, a C-terminal peptide thioester and an $\mathrm{N}$-terminal cysteinyl peptide, combine through a reversible thiol-thioester exchange process in water at neutral $\mathrm{pH}$. The peptide bond is formed from the thioester-linked intermediate by a thermodynamically favorable intramolecular acyl migration reaction from sulfur to nitrogen. Since the introduction of NCL in 1994, the scope of peptide bond formation through thiol-thioester capture was considerably extended by the development of various thioester or selenoester surrogates, thio or seleno amino acids and the application of mild dechalcogenation techniques. ${ }^{5-7}$ In particular, the desulfurization of Cys is frequently used for the preparation of peptide bonds to alanine (Ala, Figure 4b).

a)

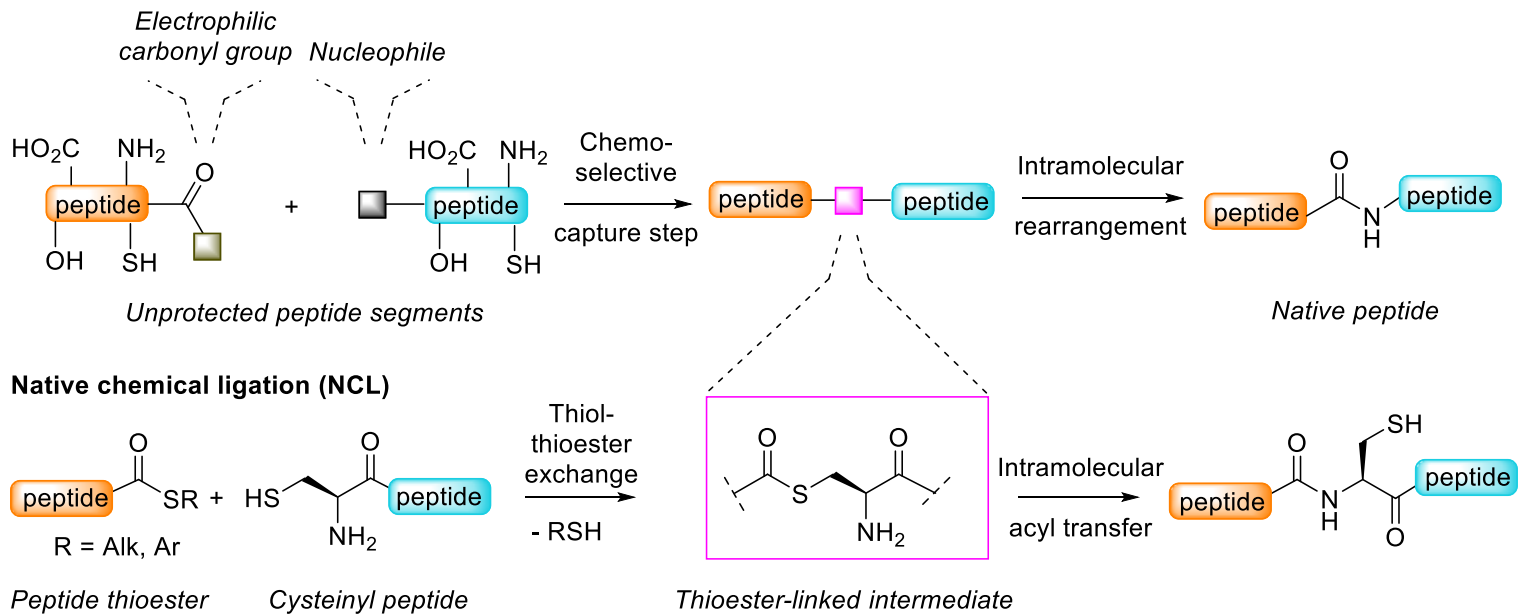

b)

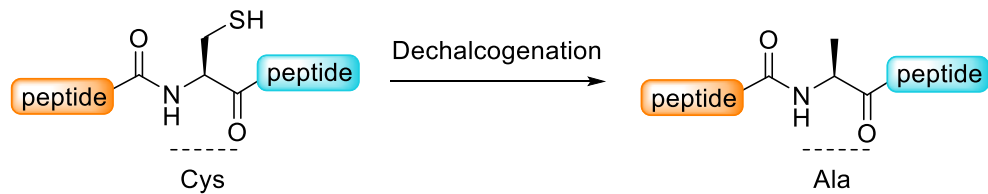

Figure 4. a) The covalent capture concept and the principle of chemoselective peptide bond forming reactions are illustrated by native chemical ligation (NCL), the first reaction of this 
kind that was introduced in 1994. b) The dechalcogenation of thio or seleno amino acids, which extends the principle of NCL to the formation of virtually any type of junction, is illustrated with the dechalcogenation of cysteine into alanine.

Living systems can produce extremely large polypeptides, but show significant limitations or require sophisticated techniques when it comes to going beyond the 20 programmable canonical amino acids. In contrast, a strong asset of protein semi or total synthesis is the use of tailored synthetic peptide segments as building blocks for the assembly of the protein, because these peptide segments can incorporate virtually any type of amino acid (e.g., D-amino acids), modification, label or prosthetic group. Functional groups may also be introduced for further in vitro or in vivo chemical manipulations or for the production of a variety of protein scaffolds such as cyclic or branched proteins. The diversity of modifications attainable through chemical synthesis facilitates the tuning of the functions and properties of therapeutic protein candidates, or the use of proteins as tools for biological investigations through proteomic or imaging studies for example.

A schematic example of protein chemical synthesis from synthetic peptide segments is provided in Figure 5a. In this case, the peptide chemist can freely decide the number, type and sites of modification. The size of the proteins attainable by this kind of approach is in the range 50-450 AAs, but is usually less than 200 AA as the number of ligations to perform above this size can be limiting. The largest proteins prepared so far by chemical synthesis ( 45-50 kDa, see PCS$\mathrm{db} \#$ in Figure 2b) can be considered as masterpieces. The assembly of four peptide segments as shown in Figure 5a gives access to proteins having an average of 150 amino acid residues, one limiting factor being the size of the peptide segments produced by conventional SPPS ( 4050 AA). The semi synthesis of a protein from two peptide modules is shown in Figure $5 \mathrm{~b}$. In this example, one reacting partner is produced recombinantly in a living organism such as 
bacteria and the other by chemical synthesis. ${ }^{7}$ In this case, the site of modification is restricted to the $\mathrm{N}$ or $\mathrm{C}$ terminal parts of the target protein, the recombinantly produced segment usually being much larger than the one accessed by chemical synthesis. Although this can restrict the application of semi-synthesis to the production of modified proteins, the approach has proven particularly powerful in several instances. Typically, the semi-synthesis of histone proteins harboring various PTMs on their N-terminal tail using expressed protein ligation $\left(\mathrm{EPL}^{8}\right)$, an adaptation of NCL to the use of peptide thioesters of biological origin, has significantly advanced the study of the histone code (for a recent review on the synthesis of modified histones see $\left.\operatorname{ref}^{9}\right)$.

a)
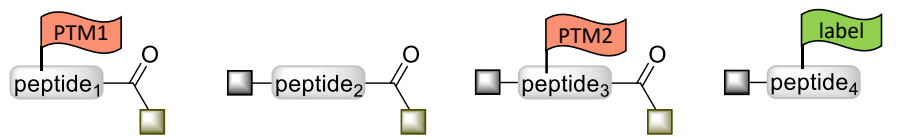

1. Multistep assembly

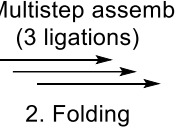

Synthetic peptide segments
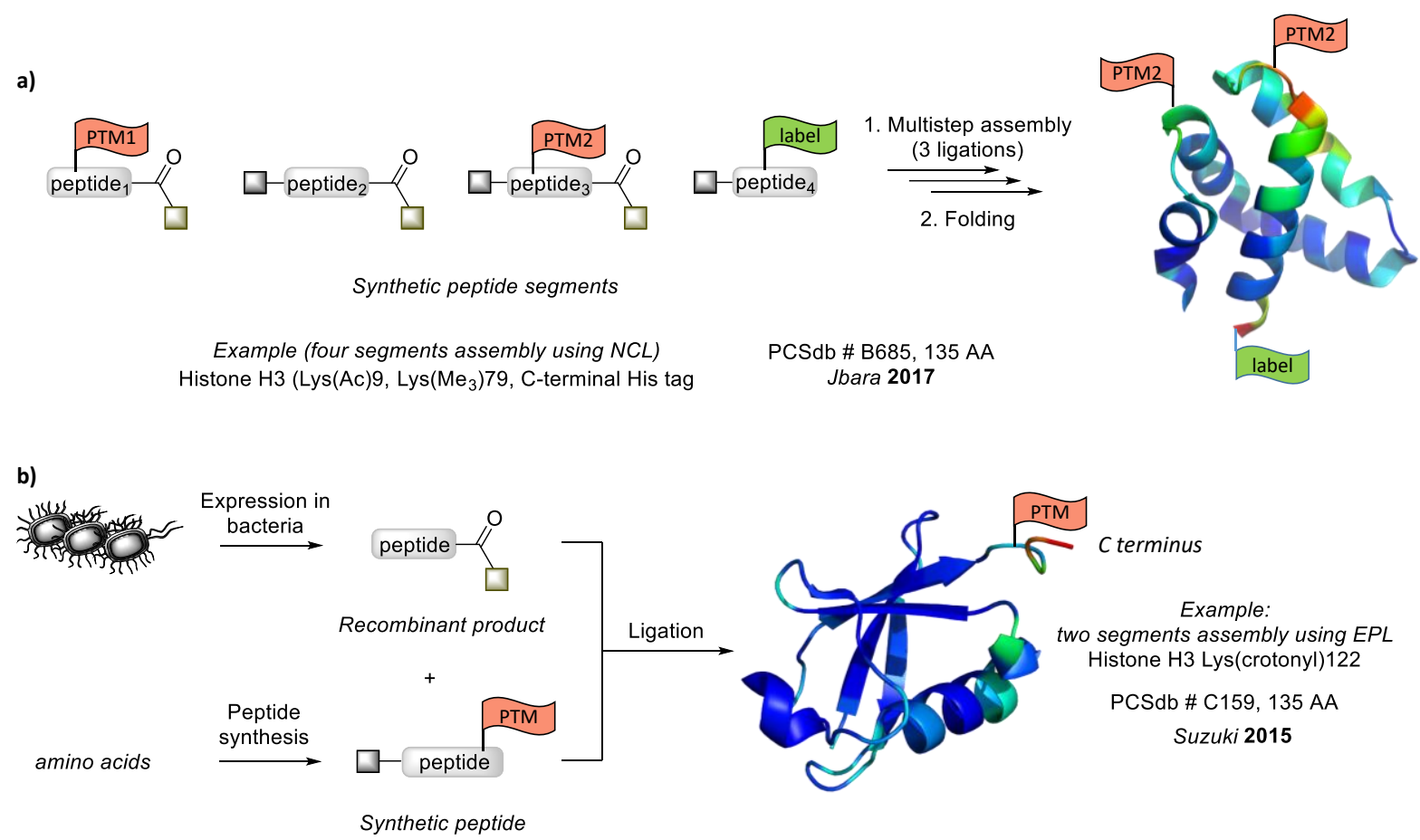

Figure 5. Principle of the total (a) or semi-synthesis (b) of proteins.

The assembly approaches can also include an enzymatic step, thereby extending the scope of targets attainable through semi or total synthesis (Figure 6). The enzymatic step can be used for 
further modifying a peptide segment before its inclusion in a protein assembly (Figure 6a). Such an approach is particularly advantageous when the target sequence features multiple sites that can be modified by the same enzyme. ${ }^{10}$ Indeed, applying the enzymatic step after assembly might yield a heterogeneous product, while such a risk does not exist if the enzymatic modification is performed on a peptide segment that features a single modification site. Chemoenzymatic methods can also be used for modifying or extending a chemical group introduced during the preparation of one of the peptide segments and utilized as a primer (Figure 6b). ${ }^{11}$ The approach has proven particularly powerful in the context of glycoprotein synthesis. $^{12}$

a)

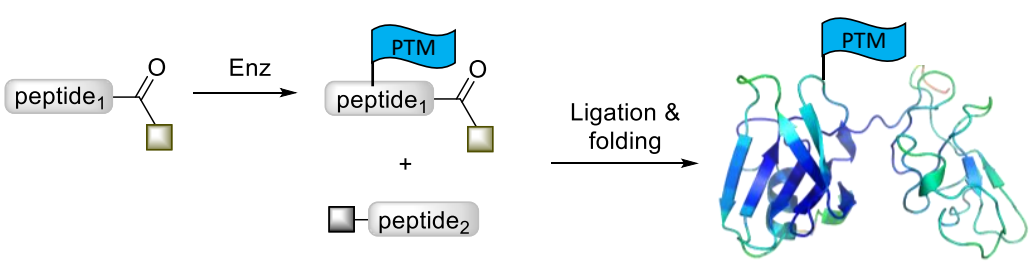

Example (enzymatic phosphorylation) PCSdb \# C179, $152 \mathrm{AA}$ Phosphorylated diubiquitin chains Pan 2019

b)

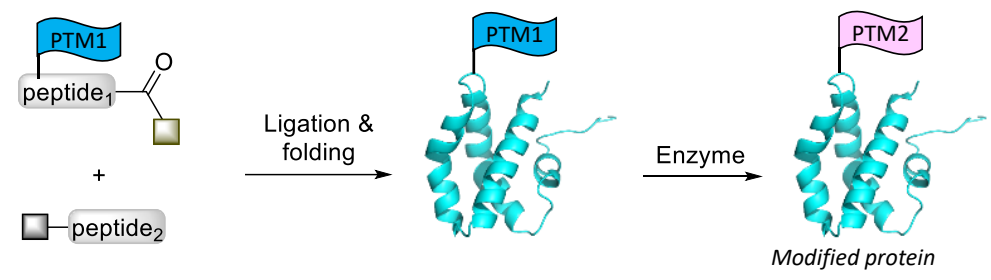

Example (enzymatic glycosylation) PCS-db \# B176, 80 AA Saposin C Hojo 2012

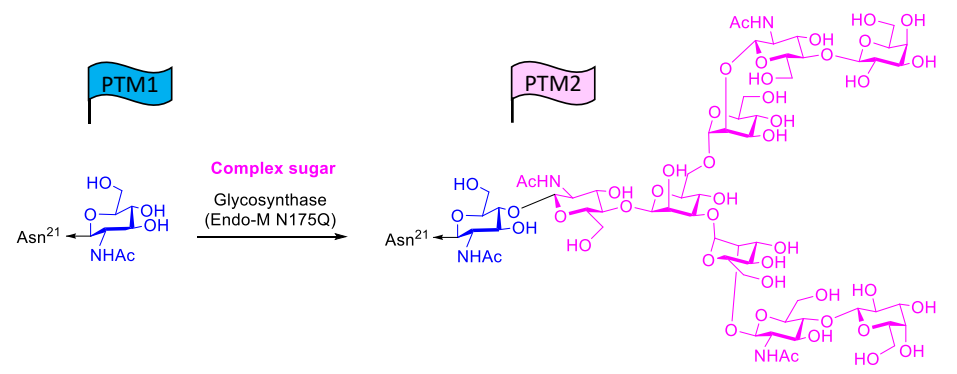

Figure 6. Some examples of chemoenzymatic approaches to protein semi or total synthesis. a) A peptide segment is modified prior to its use for protein assembly. b) A chemical group is 
introduced on one of the starting peptide segments (e.g., a monosaccharide) to enable postassembly enzymatic manipulations (e.g., coupling of a complex oligosaccharide).

\section{Protein synthesis and the role of PTMs}

As mentioned before, one hallmark of protein chemical synthesis is its capacity to access proteins that cannot be obtained recombinantly. ${ }^{13}$ Logically, a significant proportion $(\sim 50 \%)$ of the proteins prepared by semi or total synthesis are modified, that is are not solely made of the concatenation of the 20 canonical L-amino acid residues. According to the PCS-db, a large fraction of the studied modifications are post-translational modifications (Figure 7a), and include by order of importance glycosylation or mimics thereof, lysine modification by ubiquitin or ubiquitin-like modifiers, phosphorylation, lysine acetylation or methylation (Figure $7 b)$. 
a)

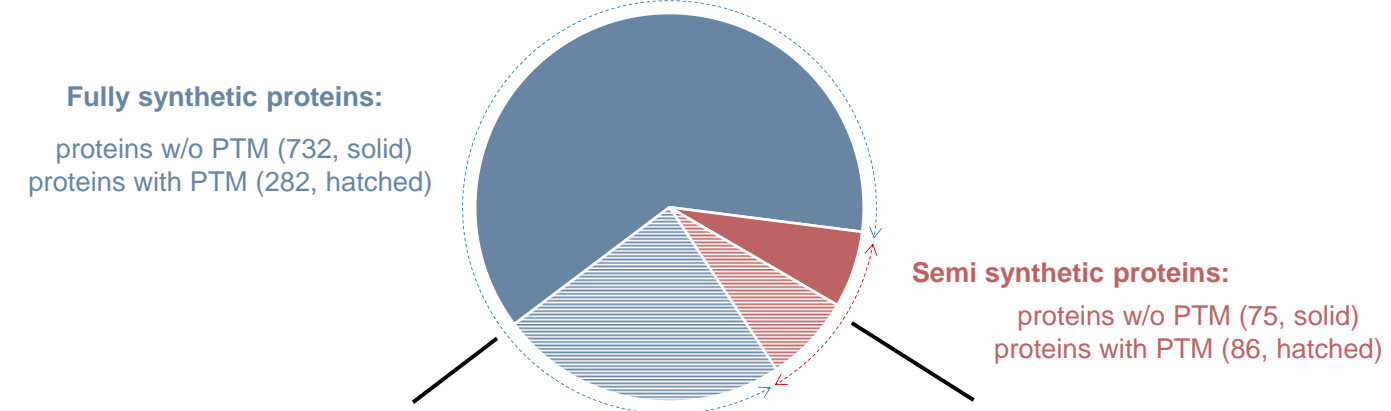

b)

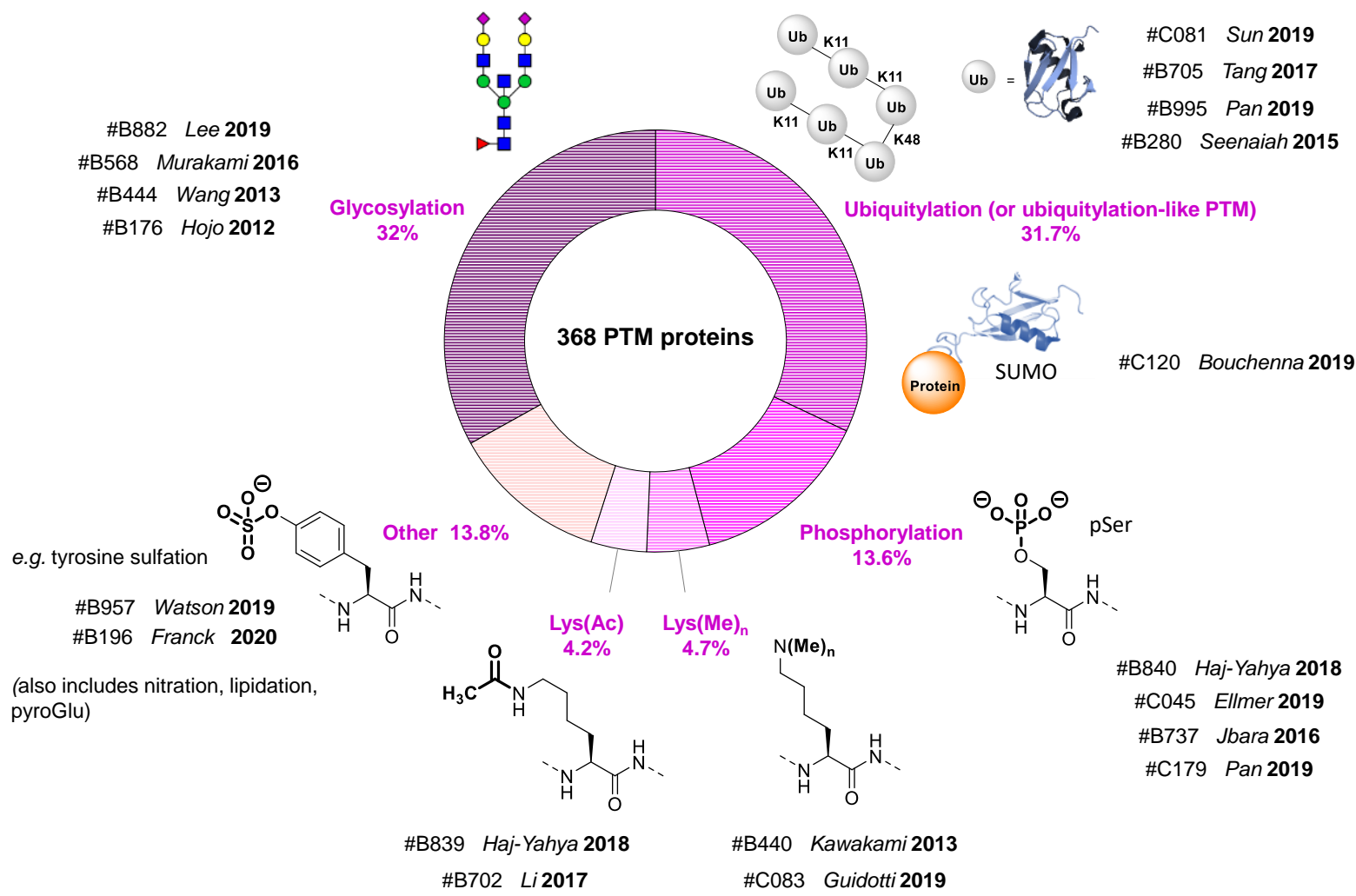

Figure 7. A large fraction of the proteins prepared by semi or total synthesis feature a posttranslational modification (other category includes sulfation, $\mathrm{N}$-terminal pyroGlu, nitration...).

From a chemistry perspective, the incorporation of these PTMs into synthetic proteins does not always represent the same amount of effort. While phosphorylated, methylated or acetylated residues are most often brought in during SPPS from commercially available or readily accessible building blocks, the production of glycosylated or ubiquitinylated targets will require the adaptation of synthetic designs and the mobilization of synthetic tools on a much broader 
level. However, proteins harboring the latter modifications paradoxically constitute the majority of achievements, a situation that reflects their increasing importance in chemical biology and medicinal chemistry (Figure 7b). In the following paragraphs, we will review the situation by providing a selection of recent examples of phosphorylated, ubiquitinylated and glycosylated protein variants exploited for studying the role of PTMs.

Protein phosphorylation or dephosphorylation is used by the cell machinery for orchestrating most cellular processes but its malfunction results in the development of diseases such as cancer, neurodegenerative disorders or diabetes. Therefore, the exploration of protein phosphorylation patterns and the identification of the enzymes involved in their regulation are key to the development of many target-based therapeutic strategies. The inability of living systems to produce substantial amounts of phosphoproteins with a full control of the phosphorylation site is, however, regarded as a serious bottleneck for deciphering the role of protein phosphorylation, for understanding signaling networks and for developing novel phosphoprotein-based therapeutics. ${ }^{14}$ Of course, the presence of phosphoserine (pSer) or phosphothreonine (pThr) can sometimes be mimicked by introducing negatively charged amino acid residues, i.e. aspartic (Asp) or glutamic (Glu) acids, or by other means that include phosphonate amino acid surrogates. ${ }^{15}$ However, the mimicry of pSer/Thr does not always succeed in reproducing the effects of phosphorylation, ${ }^{16}$ and explains why the synthesis of homogeneous phosphoproteins remains a significant goal and the focus of many synthetic efforts.

One typical example of the importance of protein phosphorylation in disease onset and progression is Tau protein phosphorylation in Alzheimer's disease (AD). An abnormal phosphorylation level of the Tau protein is an early and crucial event in the pathogenesis of AD by leading to the formation of insoluble neurofibrillary tangles. Deciphering the role of phosphorylation and other PTMs in the properties and function of the Tau protein is therefore 
recognized as an important step toward the conception of future therapeutics. ${ }^{17}$ A very recent study from Becker's group describes the semisynthesis of Tau variants featuring a pSer or a carboxymethylated lysine residue within the central repeat domain of Tau4 spanning residues 291-321, a domain involved in the binding to tubulin and in Tau aggregation. ${ }^{18}$ The phosphorylation of Ser293 or Ser305 residues decreased the propensity of Tau protein to aggregate without changing the binding to tubulin. In contrast, carboxymethylation of lysine 294, an advanced glycation end product modification that cannot be introduced enzymatically or programmed in living cells, altered the binding to tubulin without changing the aggregation behavior of Tau. Another recent report from Haj-Yahya and Lashuel also used a semisynthetic approach for installing a pSer residue in the C-terminal part of the Tau protein and for deciphering the role of this and other PTMs in healthy and diseased states. ${ }^{19}$

Ubiquitinylated proteins ${ }^{20}$ and proteins modified by ubiquitin-like modifiers such as SUMO ${ }^{21}$ are another class of modified proteins that are actively pursued by protein chemists due to the difficulty in obtaining them recombinantly. Although the role of ubiquitinylation in protein degradation by the proteasome is well established, there is increasing evidence that reversible ubiquitinylation also regulates cell cycle events through nonproteolytic mechanisms. The reversion of the (poly)ubiquitin signal is carried out by deubiquitylating enzymes (DUBs), ${ }^{22}$ which constitute potential therapeutic targets, especially for the development of anticancer drugs. ${ }^{23}$ Decoding the ubiquitin signal and characterizing the properties of DUBs is essential for making progress in this area (for reviews see ref $^{24}$ ) and already benefits from the outstanding advances made in recent years in the synthesis of polyubiquitin chains ${ }^{25-28}$ and ubiquitinylated proteins. $^{29,} 30$ The same holds true for small ubiquitin-like modifiers (SUMO), which can change the localization, the stability, or the activity of the target proteins by modulating proteinprotein interactions and by competing or intersecting with other lysine modifications such as ubiquitin. The protein chemical synthesis toolbox now enables access to SUMO conjugates 
with an atom control of their branching structure. ${ }^{21,26,31}$ Such tools are already used for characterizing the biochemical and conformational properties of SUMO isoforms ${ }^{32}$ and SUMO deconjugating enzymes (SENPs), which have emerged as potential therapeutic targets. ${ }^{33}$

The power and versatility of protein chemical synthesis for studying protein ubiquitinylation and the cross-talk between ubiquitinylation and other PTMs such as phosphorylation can be appreciated in the light of a recent study. ${ }^{10}$ Liu and coworkers reported the semisynthesis of non-phosphorylated or phosphorylated variants of Lys6-linked di-ubiquitin ( $\mathrm{Ub} \mathrm{K6} \mathrm{Ub}$ ) to investigate the link between Ub phosphorylation by PINK1 and Parkin's E3 ligase activation at the molecular level (Figure 8). ${ }^{10}$ PINK1 and Parkin's E3 ligase are key players in the quality control of mitochondria. Mitochondrial damage induces the activation of Parkin's E3 ubiquitin ligase by PINK1, an event which ultimately results in selective mitochondrial autophagy, also called mitophagy. Abnormal PINK1 and Parkin's E3 ligase functions due to gene mutation are involved in diseases such as juvenile Parkinson's disease. With the knowledge that phosphorylated monomeric ubiquitin can activate wild-type Parkin's E3 ligase (w-Parkin), Liu and coworkers embarked on the production of all four possible non-phosphorylated or phosphorylated Ub K6 Ub variants, to see which form interacts with and activates w-Parkin or phosphorylated Parkin (p-Parkin). The synthetic strategy, which is illustrated in Figure 8 with the synthesis of the diphosphorylated $\mathrm{Ub}^{\mathrm{P}} \mathrm{K} 6 \mathrm{Ub}^{\mathrm{P}}$ dimer, enabled the production of the nonphosphorylated or the monophosphorylated variants as well. The latter could be produced with a full control of the phosphorylation site because enzymatic phosphorylation was performed on each Ub domain separately and before dimer assembly. This mode of modification and assembly of phosphorylated Ub dimers follows the general strategy depicted in Figure 5a. Note that the Lys6 residue is mimicked by an $S$-(2-aminoethyl)-cysteine residue formed by reacting the glycyl cysteamine derivative aGCA on a Ub domain featuring a dehydroalanine derivative (Dha) at position 6. Because the aGCA derivative provides the C-terminal glycyl residue of the 
proximal Ub domain, the hydrazide Ub segment used as a thioester surrogate was produced recombinantly with a missing glycine at its $\mathrm{C}$-terminus. Of the four possible variants, only $\mathrm{Ub}^{\mathrm{P}}$ $\mathrm{K} 6 \mathrm{Ub}$ and $\mathrm{Ub}^{\mathrm{P}} \mathrm{K} 6 \mathrm{Ub}^{\mathrm{P}}$, which are dimers featuring a phosphorylated distal $\mathrm{Ub}$ domain, could activate w-Parkin. In contrast, $\mathrm{Ub}$ K6 $\mathrm{Ub}^{\mathrm{P}}$ equipped with a phosphorylated promixal Ub domain could only activate p-Parkin.

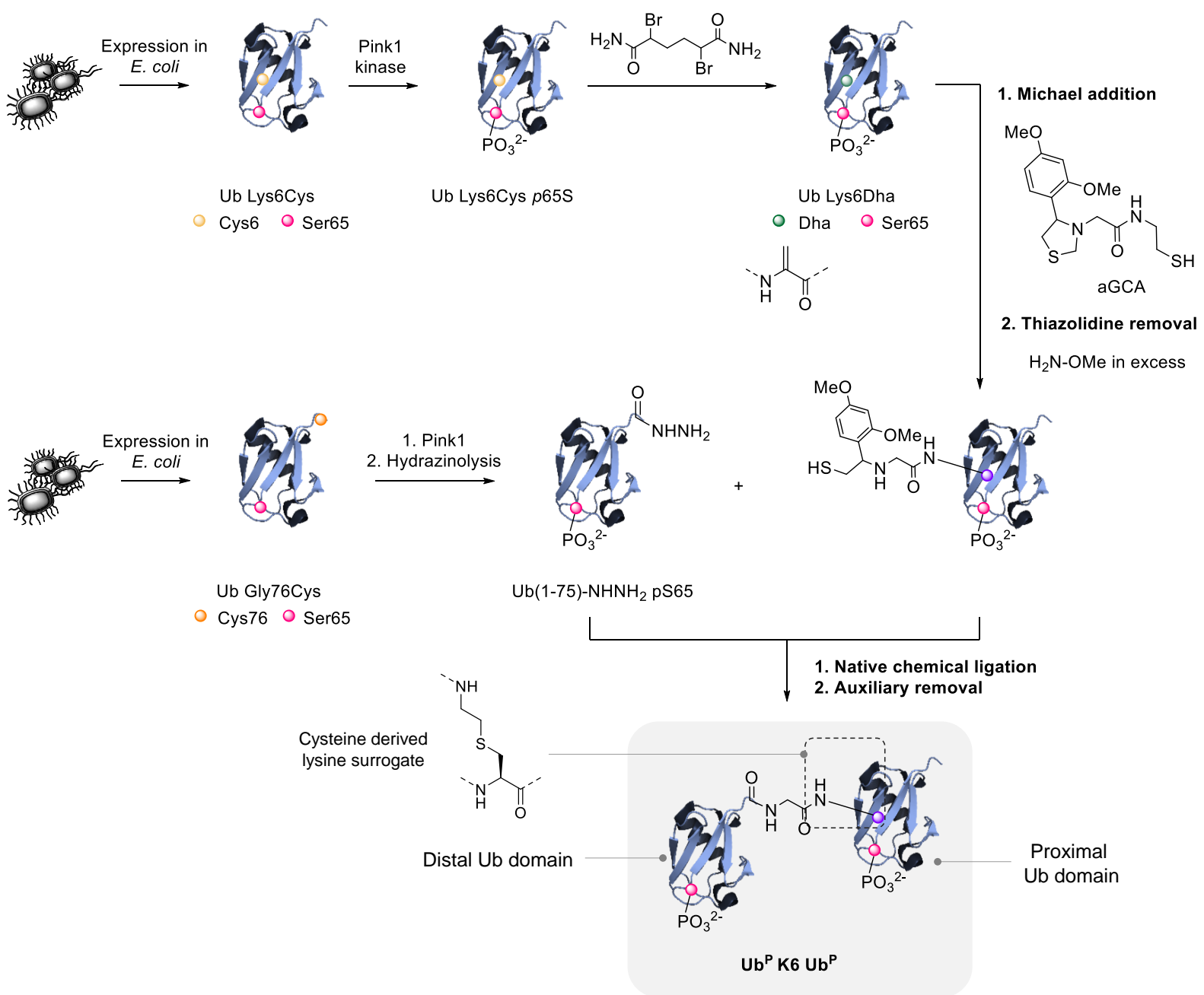

Figure 8. Semisynthetic approach to phosphorylated diubiquitins by Liu and coworkers.

In another example, Brik and coworkers used protein chemical synthesis to prepare histone protein H2B ubiquitinylated at lysine 120 (H2B K120 Ub) and histone H2A phosphorylated on 
tyrosine 57 (H2A Y57p). ${ }^{34}$ These two proteins were used to reconstitute nucleosomes and test the effect of Y57 phosphorylation on H2B K120 Ub deubiquitinylation by the Spt-Ada-Gen5 acetyltransferase (SAGA) coactivator complex. Y57 phosphorylation was found to significantly reduce ( $\sim 30$ fold) the rate of deubiquitinylation of $\mathrm{H} 2 \mathrm{~B}$ by the SAGA complex, a result that provided the first direct proof of a negative regulation of $\mathrm{H} 2 \mathrm{~B}$ deubiquitinylation by H2A Y57p. These results are consistent with the X-ray crystal structure of the SAGA DUB module bound to ubiquitinylated nucleosomes. ${ }^{35}$ Histone ubiquitinylation is a critical epigenetic mechanism regulating chromatin assembly, DNA transcription activation and DNA damage repair. Since its deregulation plays a major role in oncogenesis, histone ubiquitinylation is considered as a potential target for developing anticancer therapeutics. ${ }^{36}$ Therefore, identifying the factors regulating histone ubiquitinylation is a significant goal to pursue. Protein semi and total synthesis has already greatly contributed to enlarge our knowledge of the chromatin code and continues to play a major role in this field. ${ }^{37-39}$

Another PTM essential to the activity of many proteins is glycosylation. Understanding the relationship between the glycosylation profile or position and the properties or function of the glycoprotein is an important step in the development of glycan-based drugs. ${ }^{40}$ The study of glycoproteins is often challenging due to the difficulty in accessing substantial amounts of homogeneous protein glycoforms. Their semi or total synthesis is also particularly demanding since it requires a double expertise in oligosaccharide and protein production, which is not common. ${ }^{41}$ The outstanding efforts towards the production of homogeneous glycosylated erythropoietin (EPO) variants or surrogates are certainly regarded by all protein chemists as great achievements during the last decade. ${ }^{42-44}$ EPO glycoprotein induces the maturation of red blood cells and its glycosylation is critical for achieving full biological activity. Several EPO variants are used in the clinic for treating anemia resulting from various pathological states and in particular kidney dysfunctions. ${ }^{45}$ The development of future erythropoiesis-stimulating drugs 
heavily depends on the understanding of the relationship between the number of oligosaccharides, their composition and site of attachment and the in vivo bioactivity of EPO, an objective pursued for example by Kajihara and coworkers using synthetic ${ }^{46,47}$ or semisynthetic approaches. ${ }^{48}$

In the previous examples, the glycan moieties were produced and attached to the peptide segments prior to the assembly of the protein, according to the general strategy described in Figure 4a. An example of total chemoenzymatic synthesis of a glycoprotein that corresponds to the approach depicted in Figure 5b has been reported by Hojo et al. with the synthesis of Saposin C (80 AA). ${ }^{11}$ Saposin C activates GlcCer- $\beta$-glucosidase (GCase) and is involved in the degradation of beta-glucosylceramide (GlcCer) in lyzosomes. Deficiency in saposin C due to mutations causes a rare form of Gaucher's disease. A minimally glycosylated precursor of saposin $\mathrm{C}$ bearing an $\mathrm{N}$-acetylglucosamine (GlcNAc) residue at asparagine 21 was produced by ligating two peptide segments using NCL. It was further elaborated into saposin C carrying a complex nonasaccharide by coupling a synthetic octasaccharide to the GlcNAc residue. This saposin C product, as well as other glycoprotein analogs, was used to investigate the role of the sugar moiety on GCase activity.

Several other PTMs have been worked out by protein chemists such as protein acetylation ${ }^{49}$ and methylation $^{50}$ which are frequent in the proteome (Figure 7). Writers, readers and erasers of protein acetylation or methylation marks are the subject of intense research as therapeutic targets, and include histone deacetylases, bromodomains and protein methyltransferases. Protein synthesis has also been used to tackle less frequent PTMs such protein sulfation, ${ }^{51,52}$ nitration ${ }^{53}$ or featuring advanced glycation end products (AGE). ${ }^{18}$

\section{Protein synthesis: from target identification to protein therapeutics}


One asset of protein chemical synthesis is its capacity to access proteins harboring virtually any type of modification. Figure 9 summarizes the different categories according to which the modified proteins are classified in the PCS database. Besides the PTM-modified proteins discussed in the previous section, the other categories include backbone cyclized peptides and proteins, tagged proteins and proteins made of D-amino acids (D-proteins).

The production of proteins modified by tags is a frequent application of protein synthesis for enabling their detection or their manipulation. For example, Simonneau et al. used sitespecifically biotinylated hepatocyte growth factor (HGF) domains and streptavidin technology to study the importance of multivalency in HGF receptor activation. ${ }^{54}$ The modification can also be a reactive group designed to trap a binding partner or an enzyme. For example, the modification of $\mathrm{Ub}$ or SUMO proteins by tags and electrophilic groups proved particularly successful for detecting the conjugates formed with DUBs in an activity-based manner. ${ }^{55}$

One remarkable application of protein synthesis is the production of D-proteins. D-proteins are mirror images of L-proteins and their interest goes from structural studies to peptide or protein drug selection. Quasi-racemic mixtures of D and L-proteins have the capacity to crystallize more easily than D or L-proteins taken alone. This property is exploited in quasi-racemic X-ray crystallography for obtaining high resolution structural data for proteins that are naturally reluctant to crystallize. ${ }^{56}$ In a different application, the production of D-proteins enables the implementation of a technique called mirror-image phage display (MIPD). MIPD uses the Dprotein as bait to select L-peptide or protein binders from a randomized phage library. By symmetry, the D-analogs of the L-peptide binders obtained from the selection process can bind the natural L-protein. Made of D-amino acid residues, such peptide ligands are nonimmunogenic and significantly more stable toward proteolytic enzymes than L-peptides, making them more likely to become future drugs. The power of the approach has recently been 
illustrated by the design of a D-protein antagonist of natural vascular endothelial growth factor A (VEGF-A). ${ }^{57}$

As stated at the beginning of this Perspective article, natural product based screening is a powerful means for small molecule drug discovery ${ }^{58}$ but also for identifying and developing peptide or protein therapeutics. After the initial screening and identification step, developing a synthetic access to the hits is often needed in order to be independent of the natural source, to provide substantial quantities of compounds of interest and to give access to analogs for drug optimization. The natural protein pool is a growing source of potential protein drugs thanks to the constantly increasing performance of modern protein synthesis. The research on cyclotides is particularly representative of the contribution of modern protein synthesis to the natural product-based protein drug discovery approach. ${ }^{59}$ Cyclotides are backbone cyclized disulfide bond-stabilized small proteins produced by various plants. They have a wide range of applications in medicine by exploiting their natural bioactivity or for their capacity to acquire new functions by grafting an epitope from a bioactive peptide or protein onto the cyclotide scaffold. An analog of cyclotide kalata B1 called T20K has reached clinical trials for its immunomodulatory properties and its potential for the treatment of multiple sclerosis. ${ }^{60,61}$ Defensins, another class of cyclic peptides, have attracted widespread attention for their appealing potential as antimicrobials, antivirals and immunomodulators. In a program aiming at improving the inhibitory activity of RTD-1 against Anthrax metalloprotease, Camarero and coworkers achieved its full positional amino acid scanning using a chemical approach based on the combination of cyclative NCL and oxidative folding. ${ }^{62}$

To give another example from the PTM category, very recent reports from Payne's laboratory discuss the potential of tick-derived sulfoproteins produced by chemical synthesis for the design of thrombin inhibitors having anticoagulant activities, ${ }^{51}$ or for the development of chemokine inhibitors having promising antiinflammatory properties. ${ }^{52}$ 


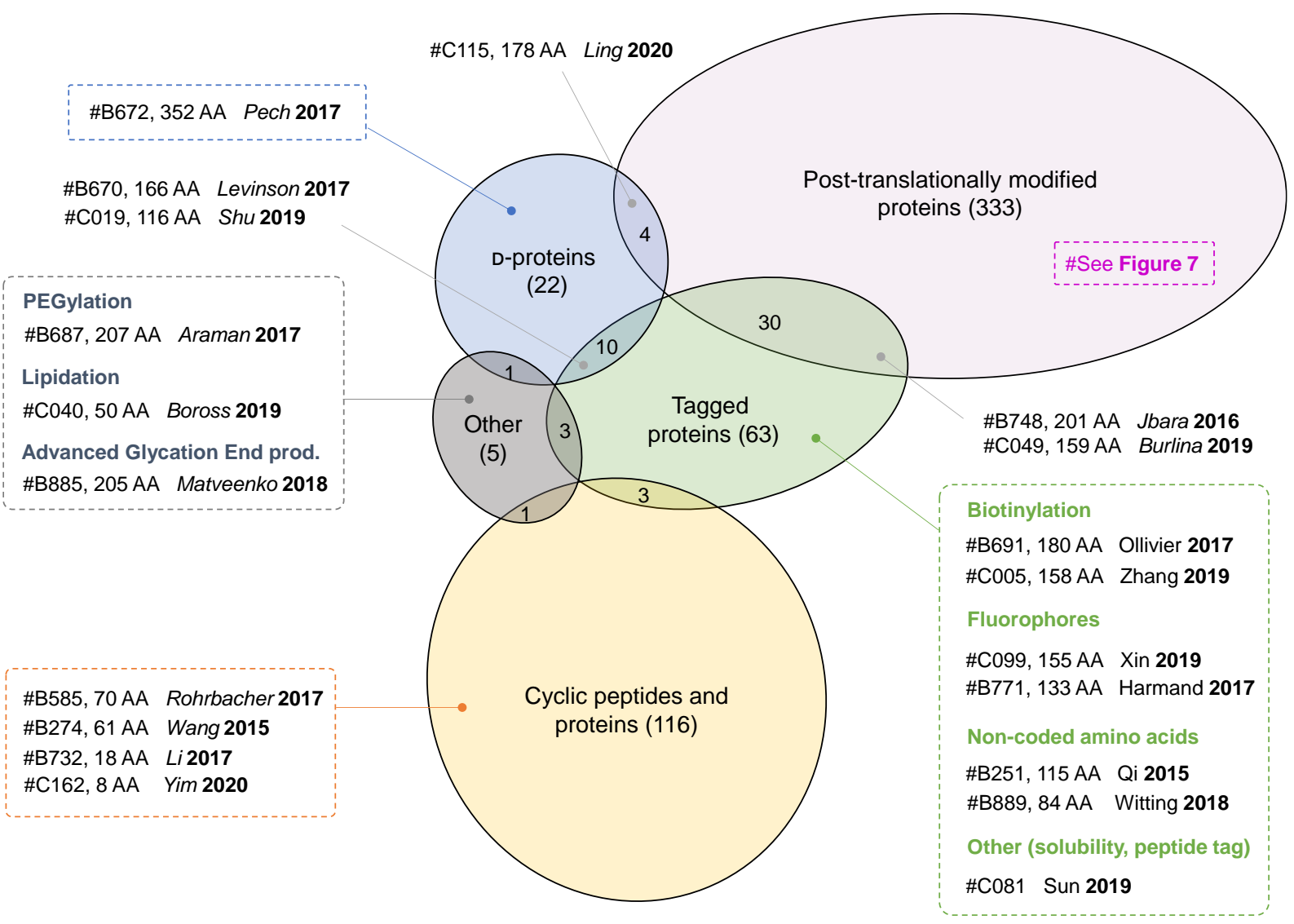

Figure 9. Modified proteins produced by semi or total synthesis are classified into five distinct categories. Note the overlap between certain categories, especially between PTM and tagged protein categories (30 proteins in common).

\section{CONCLUSION AND PERSPECTIVE COMMENT}

The growth of the field of protein therapeutics in the future will be sustained by the development of novel synthesis techniques that are more respectful of the environment. Classical SPPS methods are expensive, use toxic solvents (e.g. $N, N$-dimethylformamide) and reagents (e.g. uronium coupling agents $)^{63}$ and generate a large amount of waste. Hopefully, SPPS is already experiencing a smooth transition to greener chemistries,${ }^{64}$ which include the use of water as the solvent for the concatenation of amino acids. ${ }^{65}$ 
Another trend, which is critical to the discovery of small protein therapeutics, is the development of fast methods for the production of synthetic protein libraries. The development of fast synthesis techniques will enable full benefit from the high throughput methods that are available for screening small molecules. Recent studies show spectacular advances in synthesis time by adapting Fmoc SPPS protocols to automated flow reactors. ${ }^{66}$ The system enabled the synthesis of a functional 164 AA protein, sortase A, in a few hours. Although the equipment needed to achieve such syntheses will require some time to become popular and affordable, in the future the protein chemist will probably see a dramatic reduction of the synthesis time needed for the SPPS of small proteins or of the peptide building blocks utilized for protein assembly. We can predict that the protein assembly step itself will experience the same technological revolution with the recent development of microfluidic systems able to perform an NCL reaction in a few minutes, ${ }^{67,68}$ and eventually a post-ligation treatment such as desulfurization. ${ }^{67}$ Stimulated by the asset of solid phase chemistry for automation, developments for assembling proteins on the solid phase are also actively pursued. ${ }^{69,70}$ Complementary to the advances based on solid phase or microfluidic technologies, the field of protein chemical synthesis by peptide segment assembly will benefit from the discovery of novel ligation chemistries enabling the acceleration of protein assembly and the extension of the type of junctions that can be produced chemoselectively in water. ${ }^{71}$ Last but not least and due to their intrinsic nature, peptides and proteins will continue to raise solubility issues ${ }^{72}$ or side-reactions ${ }^{73}$ whose occurrence must be minimized for extending the scope of protein chemical synthesis.

\section{AUTHOR INFORMATION}

\section{Corresponding Authors}


*O.M.: e-mail: oleg.melnyk@ibl.cnrs.fr.

*V.A.: e-mail: vangelis.agouridas@ibl.cnrs.fr.

\section{ORCID}

Oleg Melnyk: 0000-0002-3863-5613

Vangelis Agouridas: 0000-0003-0911-1527.

Notes The authors declare no competing financial interest.

\section{Biographies}

Vangelis Agouridas obtained his Ph.D. in organic chemistry from the University of Versailles Saint-Quentin (France) in 2006. After a first postdoctoral fellowship in natural product synthesis at Boston University (USA), he returned to France for two additional fellowships in medicinal chemistry at Paris V and Paris XI faculties of pharmacy. In 2010, he was appointed assistant professor at the Ecole Nationale Supérieure de Chimie de Lille (ENSCL, France) and joined the group of Dr. Oleg Melnyk in 2013. His main research activity is focused on developing amide-bond metathesis reactions applied to peptides and proteins.

Ouafâa El Mahdi obtained her Ph.D. degree in organic chemistry from the University of Montpellier in 1997. She then joined Oleg Melnyk's team (Lille, France) for two years as postdoctoral research fellow where she developed novel biofunctionalization chemistries for hybrid nanoparticle synthesis. In 2003, she was appointed assistant professor at the University of Sidi Mohamed Ben Abdellah (Fez City, Morocco) and was promoted to full professor in 2017 at the same University. She is interested in chemical ligation methods for the synthesis of peptides and proteins. 
Oleg Melnyk graduated as an engineer in chemistry in 1989 from the Ecole Nationale de Chimie de Paris (ENSCP, France). He received his Ph.D. degree in 1994 from the University of Paris VI (France). During his thesis work, he developed a semisynthetic route to cortisone. After post-doctoral training from 1994 to 1996 in the group of Prof. A. Tartar (Lille, France) he was recruited by the Centre National de la Recherche Scientifique (CNRS) in Lille. He is now director of research at CNRS and his main research interests are the development of chemical methods for protein synthesis and the study of protein function.

\section{ACKNOWLEDGMENTS}

We acknowledge financial support from CNRS, INSERM, CHU, Univ Lille and Institut Pasteur de Lille.

\section{REFERENCES}

1. Lau, J. L.; Dunn, M. K. Therapeutic Peptides: Historical Perspectives, Current Development Trends, and Future Directions. Bioorg. Med. Chem. 2018, 26, 2700-2707.

2. Dawson, P. E.; Muir, T. W.; Clark-Lewis, I.; Kent, S. B. H. Synthesis of Proteins by Native Chemical Ligation. Science 1994, 266, 776-779.

3. Bode, J. W.; Fox, R. M.; Baucom, K. D. Chemoselective Amide Ligations by Decarboxylative Condensations of N-Alkylhydroxylamines and $\alpha$-Ketoacids. Angew. Chem. Int. Ed. 2006, 45, 1248-1252. 4. Zhang, Y.; Xu, C.; Lam, H. Y.; Lee, C. L.; Li, X. Protein Chemical Synthesis by Serine and Threonine Ligation. Proc. Natl. Acad. Sci. U. S. A. 2013, 110, 6657-6662.

5. Agouridas, V.; El Mahdi, O.; Cargoët, M.; Melnyk, O. A Statistical View of Protein Chemical Synthesis Using NCL and Extended Methodologies. Bioorg. Med. Chem. 2017, 25, 4938-4945. 
6. Agouridas, V.; El Mahdi, O.; Diemer, V.; Cargoet, M.; Monbaliu, J.-C. M.; Melnyk, O. Native Chemical Ligation and Extended Methods. Mechanisms, Catalysis, Scope and Limitations. Chem. Rev. 2019, 12, 7328-7443.

7. Conibear, A. C.; Watson, E. E.; Payne, R. J.; Becker, C. F. W. Native Chemical Ligation in Protein Synthesis and Semi-Synthesis. Chem. Soc. Rev. 2018, 47, 9046-9068.

8. Muir, T. W.; Sondhi, D.; Cole, P. A. Expressed Protein Ligation: A General Method for Protein Engineering. Proc. Natl. Acad. Sci. U. S. A. 1998, 95, 6705-6710.

9. Nakatsu, K.; Hayashi, G.; Okamoto, A. Toolbox for Chemically Synthesized Histone Proteins. Curr. Opin. Chem. Biol. 2020, 58, 10-19.

10. Pan, M.; Zheng, Q.; Gao, S.; Qu, Q.; Yu, Y.; Wu, M.; Lan, H.; Li, Y.; Liu, S.; Li, J.; Sun, D.; Lu, L.; Wang, T.; Zhang, W.; Wang, J.; Li, Y.; Hu, H.-G.; Tian, C.; Liu, L. Chemical Synthesis of Structurally Defined Phosphorylated Ubiquitins Suggests Impaired Parkin Activation by Phosphorylated Ubiquitins with a Non-Phosphorylated Distal Unit. CCS Chemistry 2019, 1, 476-489.

11. Hojo, H.; Tanaka, H.; Hagiwara, M.; Asahina, Y.; Ueki, A.; Katayama, H.; Nakahara, Y.; Yoneshige, A.; Matsuda, J.; Ito, Y.; Nakahara, Y. Chemoenzymatic Synthesis of Hydrophobic Glycoprotein: Synthesis of Saposin C Carrying Complex-Type Carbohydrate. J. Org. Chem. 2012, 77, $9437-9446$.

12. Li, C.; Wang, L.-X. Chemoenzymatic Methods for the Synthesis of Glycoproteins. Chem. Rev. $2018,118,8359-8413$.

13. Liu, L. Chemical Synthesis of Proteins That Cannot Be Obtained Recombinantly. Isr. J. Chem. 2019, 59, 64-70.

14. Oza, J. P.; Aerni, H. R.; Pirman, N. L.; Barber, K. W.; ter Haar, C. M.; Rogulina, S.; Amrofell, M. B.; Isaacs, F. J.; Rinehart, J.; Jewett, M. C. Robust Production of Recombinant Phosphoproteins Using Cell-Free Protein Synthesis. Nat. Commun. 2015, 6, 8168.

15. Chen, Z.; Cole, P. A. Synthetic Approaches to Protein Phosphorylation. Curr. Opin. Chem. Biol. $2015,28,115-122$. 
16. Paleologou, K. E.; Schmid, A. W.; Rospigliosi, C. C.; Kim, H.-Y.; Lamberto, G. R.; Fredenburg, R. A.; Lansbury, P. T.; Fernandez, C. O.; Eliezer, D.; Zweckstetter, M.; Lashuel, H. A. Phosphorylation at Ser-129 but Not the Phosphomimics S129E/D Inhibits the Fibrillation of $\alpha$-Synuclein. J. Biol. Chem. 2008, 283, 16895-16905.

17. Šimić, G.; Babić Leko, M.; Wray, S.; Harrington, C.; Delalle, I.; Jovanov-Milošević, N.; Bažadona, D.; Buée, L.; De Silva, R.; Di Giovanni, G.; Wischik, C.; Hof, P. R. Tau Protein Hyperphosphorylation and Aggregation in Alzheimer's Disease and Other Tauopathies, and Possible Neuroprotective Strategies. Biomolecules 2016, 6, 6 .

18. Ellmer, D.; Brehs, M.; Haj-Yahya, M.; Lashuel, H. A.; Becker, C. F. W. Single Posttranslational Modifications in the Central Repeat Domains of Tau4 Impact Its Aggregation and Tubulin Binding. Angew. Chem. Int. Ed. 2019, 58, 1616-1620.

19. Haj-Yahya, M.; Lashuel, H. A. Protein Semisynthesis Provides Access to Tau Disease-Associated Post-Translational Modifications (PTMs) and Paves the Way to Deciphering the Tau PTM Code in Health and Diseased States. J. Am. Chem. Soc. 2018, 140, 6611-6621.

20. Burlina, F.; Abdel-Aal, A.-B. M.; Raz, R.; Pinzuti, I.; Papageorgiou, G.; Li, J.; Antrobus, R.; Martin, S. R.; Kunzelmann, S.; Stieglitz, B.; Offer, J. Auxiliary-Assisted Chemical Ubiquitylation of Nemo and Linear Extension by HOIP. Commun. Chem. 2019, 2, 111.

21. Bouchenna, J.; Sénéchal, M.; Drobecq, H.; Vicogne, J.; Melnyk, O. Total Chemical Synthesis of All SUMO-2/3 Dimer Combinations. Bioconjugate Chem. 2019, 30, 2967-2973.

22. Clague, M. J.; Urbé, S.; Komander, D. Breaking the Chains: Deubiquitylating Enzyme Specificity Begets Function. Nat. Rev. Mol. Cell Biol. 2019, 20, 338-352.

23. Yuan, T.; Yan, F.; Ying, M.; Cao, J.; He, Q.; Zhu, H.; Yang, B. Inhibition of Ubiquitin-Specific Proteases as a Novel Anticancer Therapeutic Strategy. Frontiers in Pharmacology 2018, 9, 1080.

24. van Tilburg, G. B.; Elhebieshy, A. F.; Ovaa, H. Synthetic and Semi-Synthetic Strategies to Study Ubiquitin Signaling. Curr. Opin. Struct. Biol. 2016, 38, 92-101. 
25. Tang, S.; Liang, L.-J.; Si, Y.-Y.; Gao, S.; Wang, J.-X.; Liang, J.; Mei, Z.; Zheng, J.-S.; Liu, L. Practical Chemical Synthesis of Atypical Ubiquitin Chains by Using an Isopeptide-Linked Ub Isomer. Angew. Chem. Int. Ed. 2017, 56, 13333-13337.

26. Bondalapati, S.; Eid, E.; Mali, S. M.; Wolberger, C.; Brik, A. Total Chemical Synthesis of SUMO2-Lys63-Linked Diubiquitin Hybrid Chains Assisted by Removable Solubilizing Tags. Chem. Sci. 2017, 8, 4027-4034.

27. Qu, Q.; Pan, M.; Gao, S.; Zheng, Q.-Y.; Yu, Y.-Y.; Su, J.-C.; Li, X.; Hu, H.-G. A Highly Efficient Synthesis of Polyubiquitin Chains. Adv. Sci. 2018, 5, 1800234.

28. Pan, M.; Zheng, Q.; Ding, S.; Zhang, L.; Qu, Q.; Wang, T.; Hong, D.; Ren, Y.; Liang, L.; Chen, C.; Mei, Z.; Liu, L. Chemical Protein Synthesis Enabled Mechanistic Studies on the Molecular Recognition of K27-Linked Ubiquitin Chains. Angew. Chem. Int. Ed. 2019, 58, 2627-2631.

29. Sun, H.; Brik, A. The Journey for the Total Chemical Synthesis of a 53 kDa Protein. Acc. Chem. Res. 2019, 52, 3361-3371.

30. Bondalapati, S.; Jbara, M.; Brik, A. Expanding the Chemical Toolbox for the Synthesis of Large and Uniquely Modified Proteins. Nat. Chem. 2016, 8, 407-418.

31. Weller, C. E.; Dhall, A.; Ding, F.; Linares, E.; Whedon, S. D.; Senger, N. A.; Tyson, E. L.; Bagert, J. D.; Li, X.; Augusto, O.; Chatterjee, C. Aromatic Thiol-Mediated Cleavage of N-O Bonds Enables Chemical Ubiquitylation of Folded Proteins Nat. Commun. 2016, 7, 12979.

32. Bouchenna, J.; Sénéchal, M.; Drobecq, D.; Stankovic-Valentin, N.; Vicogne, J.; Melnyk, O. The Role of the Conserved SUMO-2/3 Cysteine Residue on Domain Structure Investigated Using Protein Chemical Synthesis. Bioconjugate Chem. 2019, 30, 2684-2696.

33. Jia, Y.; Claessens, L. A.; Vertegaal, A. C. O.; Ovaa, H. Chemical Tools and Biochemical Assays for SUMO Specific Proteases (SENPs). ACS Chem. Biol. 2019, 14, 2389-2395.

34. Jbara, M.; Maity, S. K.; Morgan, M.; Wolberger, C.; Brik, A. Chemical Synthesis of Phosphorylated Histone $\mathrm{H} 2 \mathrm{~A}$ at Tyr57 Reveals Insight into the Inhibition Mode of the SAGA Deubiquitinating Module. Angew. Chem. Int. Ed. 2016, 55, 4972-4976. 
35. Morgan, M. T.; Haj-Yahya, M.; Ringel, A. E.; Bandi, P.; Brik, A.; Wolberger, C. Structural Basis for Histone H2B Deubiquitination by the SAGA Dub Module. Science 2016, 351, 725.

36. Jeusset, L. M.-P.; McManus, K. J. Developing Targeted Therapies That Exploit Aberrant Histone Ubiquitination in Cancer. Cells 2019, 8, 165.

37. Qi, Y.-K.; Ai, H.-S.; Li, Y.-M.; Yan, B. Total Chemical Synthesis of Modified Histones Frontiers in Chemistry 2018, 6, 19.

38. Boichenko, I.; Fierz, B., Chemical and Biophysical Methods to Explore Dynamic Mechanisms of Chromatin Silencing. Curr. Opin. Chem. Biol. 2019, 51, 1-10.

39. Dann, G. P.; Liszczak, G. P.; Bagert, J. D.; Müller, M. M.; Nguyen, U. T. T.; Wojcik, F.; Brown, Z. Z.; Bos, J.; Panchenko, T.; Pihl, R.; Pollock, S. B.; Diehl, K. L.; Allis, C. D.; Muir, T. W. ISWI Chromatin Remodellers Sense Nucleosome Modifications to Determine Substrate Preference. Nature 2017, 548, 607-611.

40. Valverde, P.; Ardá, A.; Reichardt, N. C.; Jiménez-Barbero, J.; Gimeno, A. Glycans in Drug Discovery. MedChemComm 2019, 10, 1678-1691.

41. Carlo, U.; Yasuhiro, K. Recent Advances in the Chemical Synthesis of N-Linked Glycoproteins. Curr. Opin. Chem. Biol. 2018, 46, 130-137.

42. Payne, R. J. Total Synthesis of Erythropoietin through the Development and Exploitation of Enabling Synthetic Technologies. Angew. Chem. Int. Ed. 2013, 52, 505-507.

43. Fernández-Tejada, A.; Brailsford, J.; Zhang, Q.; Shieh, J. H.; Moore, M. A. S.; Danishefsky, S. J. T. Total Synthesis of Glycosylated Proteins. In Protein Ligation and Total Synthesis I. Topics in Current Chemistry, Liu, L., Ed. Springer: Cham, 2014; Vol. 362, 1-26.

44. Wang, P.; Dong, S.; Brailsford, J. A.; Iyer, K.; Townsend, S. D.; Zhang, Q.; Hendrickson, R. C.; Shieh, J.; Moore, M. A.; Danishefsky, S. J. At Last: Erythropoietin as a Single Glycoform. Angew. Chem. Int. Ed. 2012, 51, 11576-11584.

45. Foley, R. N. Emerging Erythropoiesis-Stimulating Agents. Nat. Rev. Nephrol. 2010, 6, 218-223. 
46. Murakami, M.; Okamoto, R.; Izumi, M.; Kajihara, Y. Chemical Synthesis of an Erythropoietin Glycoform Containing a Complex-Type Disialyloligosaccharide. Angew. Chem. Int. Ed. 2012, 51, 35673572.

47. Murakami, M.; Kiuchi, T.; Nishihara, M.; Tezuka, K.; Okamoto, R.; Izumi, M.; Kajihara, Y. Chemical Synthesis of Erythropoietin Glycoforms for Insights into the Relationship between Glycosylation Pattern and Bioactivity. Sci. Adv. 2016, 2, e1500678.

48. Hirano, K.; Macmillan, D.; Tezuka, K.; Tsuji, T.; Kajihara, Y. Design and Synthesis of a Homogeneous Erythropoietin Analogue with Two Human Complex-Type Sialyloligosaccharides: Combined Use of Chemical and Bacterial Protein Expression Methods. Angew. Chem. Int. Ed. 2009, 48, 9557-9560.

49. Ali, I.; Conrad, R. J.; Verdin, E.; Ott, M. Lysine Acetylation Goes Global: From Epigenetics to Metabolism and Therapeutics. Chem. Rev. 2018, 118, 1216-1252.

50. Luo, M. Chemical and Biochemical Perspectives of Protein Lysine Methylation. Chem. Rev. 2018, 118, 6656-6705.

51. Watson, E. E.; Ripoll-Rozada, J.; Lee, A. C.; Wu, M. C. L.; Franck, C.; Pasch, T.; Premdjee, B.; Sayers, J.; Pinto, M. F.; Martins, P. M.; Jackson, S. P.; Pereira, P. J. B.; Payne, R. J. Rapid Assembly and Profiling of an Anticoagulant Sulfoprotein Library. Proc. Natl. Acad. Sci. U. S. A. 2019, 116, 1387313878.

52. Franck, C.; Foster, S. R.; Johansen-Leete, J.; Chowdhury, S.; Cielesh, M.; Bhusal, R. P.; Mackay, J. P.; Larance, M.; Stone, M. J.; Payne, R. J., Semisynthesis of an Evasin from Tick Saliva Reveals a Critical Role of Tyrosine Sulfation for Chemokine Binding and Inhibition. Proc. Natl. Acad. Sci. U. S. A. 2020, $117,2657-12664$.

53. Burai, R.; Ait-Bouziad, N.; Chiki, A.; Lashuel, H. A. Elucidating the Role of Site-Specific Nitration of $\alpha$-Synuclein in the Pathogenesis of Parkinson's Disease via Protein Semisynthesis and Mutagenesis. J. Am. Chem. Soc. 2015, 137, 5041-5052. 
54. Simonneau, C.; Berenice, L.; Mougel, A.; Adriaenssens, E.; Paquet, C.; Raibaut, L.; Ollivier, N.; Drobecq, H.; Marcoux, J.; Cianferani, S.; Tulasne, D.; de Jonge, H.; Melnyk, O.; Vicogne, J. SemiSynthesis of a HGF/SF Kringle One (K1) Domain Scaffold Generates a Potent in Vivo Met Receptor Agonist. Chem. Sci. 2015, 6, 2110-2121.

55. Ovaa, H.; Vertegaal, A. C. O. Probing Ubiquitin and SUMO Conjugation and Deconjugation. Biochem. Soc. Trans. 2018, 46, 423-436.

56. Kent, S. B. Racemic \& Quasi-Racemic Protein Crystallography Enabled by Chemical Protein Synthesis. Curr. Opin. Chem. Biol. 2018, 46, 1-9.

57. Uppalapati, M.; Lee, D. J.; Mandal, K.; Li, H.; Miranda, L. P.; Lowitz, J.; Kenney, J.; Adams, J. J.; Ault-Riché, D.; Kent, S. B. H.; Sidhu, S. S. A Potent D-Protein Antagonist of VEGF-A Is Nonimmunogenic, Metabolically Stable, and Longer-Circulating in Vivo. ACS Chem. Biol. 2016, 11, 1058-1065.

58. Harvey, A. L.; Edrada-Ebel, R.; Quinn, R. J. The Re-Emergence of Natural Products for Drug Discovery in the Genomics Era. Nat. Rev. Drug Discov. 2015, 14, 111-129.

59. De Veer, S. J.; Kan, M.-W.; Craik, D. J. Cyclotides: From Structure to Function. Chem. Rev. 2019, $119,12375-12421$.

60. Gründemann, C.; Stenberg, K. G.; Gruber, C. W. T20K: An Immunomodulatory Cyclotide on Its Way to the Clinic. Int. Pept. Res. Therap. 2019, 25, 9-13.

61. Thell, K.; Hellinger, R.; Sahin, E.; Michenthaler, P.; Gold-Binder, M.; Haider, T.; Kuttke, M.; Liutkevičiūtè, Z.; Göransson, U.; Gründemann, C.; Schabbauer, G.; Gruber, C. W. Oral Activity of a Nature-Derived Cyclic Peptide for the Treatment of Multiple Sclerosis. Proc. Natl. Acad. Sci. U. S. A. 2016, 113, 3960-3965.

62. Li, Y.; Gould, A.; Aboye, T.; Bi, T.; Breindel, L.; Shekhtman, A.; Camarero, J. A. Full Sequence Amino Acid Scanning of $\Theta$-Defensin RTD-1 Yields a Potent Anthrax Lethal Factor Protease Inhibitor. J. Med. Chem. 2017, 60, 1916-1927. 
63. McKnelly, K. J.; Sokol, W.; Nowick, J. S. Anaphylaxis Induced by Peptide Coupling Agents: Lessons Learned from Repeated Exposure to HATU, HBTU, and HCTU. J. Org. Chem. 2020, 85, 17641768.

64. Al Musaimi, O.; de la Torre, B. G.; Albericio, F. Greening Fmoc/tBu Solid-Phase Peptide Synthesis. Green Chem. 2020, 22, 996-1018.

65. Knauer, S.; Koch, N.; Uth, C.; Meusinger, R.; Avrutina, O.; Kolmar, H. Sustainable Peptide Synthesis Enabled by a Transient Protecting Group. Angew. Chem. Int. Ed. 2020, 59, 2-9.

66. Hartrampf, N.; Saebi, A.; Poskus, M.; Gates, Z. P.; Callahan, A. J.; Cowfer, A. E.; Hanna, S.; Antilla, S.; Schissel, C. K.; Quartararo, A. J.; Ye, X.; Mijalis, A. J.; Simon, M. D.; Loas, A.; Liu, S.; Jessen, C.; Nielsen, T. E.; Pentelute, B. L. Synthesis of Proteins by Automated Flow Chemistry. Science 2020, 368, 980-987. 67. Chisholm, T. S.; Clayton, D.; Dowman, L. J.; Sayers, J.; Payne, R. J. Native Chemical LigationPhotodesulfurization in Flow. J. Am. Chem. Soc. 2018, 29, 9020-9024.

68. Ollivier, N.; Toupy, T.; Hartkoorn, R. C.; Desmet, R.; Monbaliu, J.-C. M.; Melnyk, O. Accelerated Microfluidic Native Chemical Ligation at Difficult Amino Acids toward Cyclic Peptides Nat. Commun. 2018, 9, 2847.

69. Agouridas, V.; Diemer, V.; Melnyk, O. Strategies and Open Questions in Solid-Phase Protein Chemical Synthesis. Curr. Opin. Chem. Biol. 2020, 58, 1-9.

70. Ollivier, N.; Desmet, R.; Drobecq, H.; Blanpain, A.; Boll, E.; Leclercq, B.; Mougel, A.; Vicogne, J.; Melnyk, O. A Simple and Traceless Solid Phase Method Simplifies the Assembly of Large Peptides and the Access to Challenging Proteins. Chem. Sci. 2017, 8, 5362-5370

71. Dunkelmann, D. L.; Hirata, Y.; Totaro, K. A.; Cohen, D. T.; Zhang, C.; Gates, Z. P.; Pentelute, B. L. Amide-Forming Chemical Ligation via O-Acyl Hydroxamic Acids. Proc. Natl. Acad. Sci. U. S. A. 2018, $115,3752-3757$.

72. Li, J.-B.; Tang, S.; Zheng, J.-S.; Tian, C.-L.; Liu, L. Removable Backbone Modification Method for the Chemical Synthesis of Membrane Proteins. Acc. Chem. Res. 2017, 50, 1143-1153. 
73. Neumann, K.; Farnung, J.; Baldauf, S.; Bode, J. W. Prevention of Aspartimide Formation During Peptide Synthesis Using Cyanosulfurylides as Carboxylic Acid-Protecting Groups. Nat. Commun. 2020, $11,982$. 
Table of content

\section{Protein chemical synthesis in medicinal chemistry}

Vangelis Agouridas, ${ }^{\text {a* }}$ Ouafâa ElMahdi, ${ }^{\mathrm{b}}$ Oleg Melnyk ${ }^{\mathrm{a} *}$

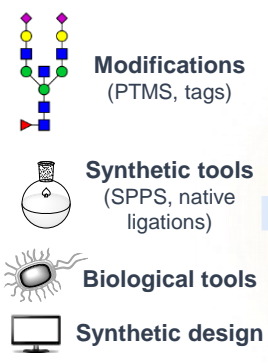

Native or modified

proteins

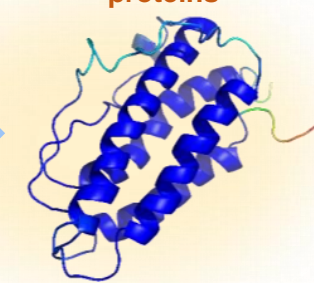

